\title{
Increased Nitrogen Retention after Trans-0perative Intravenous Amino Acid and Glucose Infusion, without Changes in Urinary Amino Acid, Adrenaline and Plasma Urea or Glucose
}

\author{
Ernann Tenorio Albuquerque-Filho', Mario Jorge Juca ${ }^{2}$, Gilberto Joao Padovan ${ }^{3}$, \\ Julio Sergio Marchini ${ }^{*}$ \\ ${ }^{1}$ Maceió University Hospital, Federal University and Coordination Alagoas State Urgency Service, Maceió, Brazil \\ ${ }^{2}$ Maceió University Hospital, Coloproctology, Alagoas Federal University, Maceió, Brazil \\ ${ }^{3}$ Division of Nutrology, Department of Internal Medicine, Faculty of Medicine of Ribeirão Preto, University of \\ São Paulo, Ribeirão Preto, Brazil \\ Email: "jsmarchi@fmrp.usp.br
}

Received 28 February 2014; revised 2 April 2014; accepted 11 April 2014

Copyright (C) 2014 by authors and Scientific Research Publishing Inc.

This work is licensed under the Creative Commons Attribution International License (CC BY).

http://creativecommons.org/licenses/by/4.0/

c) (i) Open Access

\section{Abstract}

Objective: Nutritional deficiencies are associated with increased morbidity and mortality during and after surgery. The present study evaluated nitrogen retention after transoperative intravenous infusion of amino acids and glucose. Design: Prospective study. Setting: Large community hospital. Patients: 18 randomly chosen patients undergoing medium or major surgeries. Interventions and Measurements: The experimental design included a 12-hour period before surgery (P1), a trans-operative period of 6 hours (P2), an early postoperative period (P3, 18 hours), and a late postoperative period ( $\mathrm{P} 4,24$ hours). Urinary amino acid and nitrogen were analyzed from $\mathrm{P1}$ through P4. Group I, nine patients, received Ringer's lactate solution with $5 \%$ glucose, and Group II, another nine patients, received a $6.6 \%$ amino acid and $16.6 \%$ glucose solution over a 6 -hour trans-operative period (P2) starting from the anesthesia procedures. All surgical procedures lasted a maximum of 3 hours. Results: There was no statistically significant difference in urinary amino acid or adrenaline excretion between P1 and P4 in either group. Nitrogen excretion values were also similar for both groups, i.e., $0.39 \pm 0.16$ and $0.39 \pm 0.28 \mathrm{~g} / \mathrm{hour}$, respectively. The nitrogen balance showed greater nitrogen retention $(-0.25 \pm 0.24 \mathrm{~g} / \mathrm{hour})$ in the group receiving the amino acid infusion compared to the group receiving Ringer's lactate solution $(-0.59 \pm 0.26$

"Corresponding author.

How to cite this paper: Albuquerque-Filho, E.T., et al. (2014) Increased Nitrogen Retention after Trans-Operative Intravenous Amino Acid and Glucose Infusion, without Changes in Urinary Amino Acid, Adrenaline and Plasma Urea or Glucose. Health, 6, 1012-1018. http://dx.doi.org/10.4236/health.2014.610127 
g/hour) ( $P$ < 0.05). Blood plasma urea nitrogen and glycaemia did not increase at the end of the study (P4 period) in either group. Conclusion: These data indicate that trans-operative infusion of glucose and amino acids can be beneficial for patients submitted to surgical stress in terms of nitrogen retention.

\section{Keywords}

\section{Nutrition, Surgery, Protein Metabolism, Amino Acids, Adrenaline}

\section{Introduction}

Surgically advances in parenteral and enteral feeding have created the foundation of perioperative metabolic care, which includes better identification of malnourished patients [1]. Thus, the offer of nutrients before, during or after an anesthetic procedure may be beneficial to patient undergoing surgery, resulting in a lower prevalence of postoperative co-morbidity [2] [3]. In parallel, the postoperative use of amino acid solutions reduces protein loss and/or improves the nitrogen balance after surgery [4]. However, the use of trans-operative intravenous glucose [5] [6], or a routine perioperative formula enriched with arginine, gamma-3-fatty acid and RNA [7], does not have any beneficial effect on surgical patients.

Data regarding nitrogen retention during the trans-operative period are scarce. Since surgical procedures may lead to changes in protein metabolism, the objective of the present study was to determine whether the intravenous infusion of amino acids and glucose during the trans-operative period could alter urinary nitrogen and amino acid excretion, and therefore improve the nitrogen balance 18 to 48 hours after surgery, without increasing stress (urinary adrenaline excretion).

\section{Methods and Materials}

The study was conducted on 18 patients submitted to medium or major surgeries classified according to the criteria of the American Society of Anesthesiology [8], at the general surgery service of the University Hospital, Federal University of Alagoas, Brazil, and approved by the local Ethics Committee. The anesthesia procedure was the same for all patients.

Exclusion criteria were pregnancy, digestive diseases with impaired absorption, chronic diarrhea, acute liver failure, acquired immunodeficiency syndrome, renal failure, diabetes mellitus, thyroid disorders and trans-operative cardiac arrest. No patient was on drugs that could affect catecholamine or cytokine metabolism.

The selected patients were randomly assigned to two groups of 9 individuals each (Table 1). Figure 1 shows the experimental design. Group I was submitted to the standard procedures of the hospital, receiving Ringer's lactate solution in combination with $500 \mathrm{~mL}$ of a $5 \%$ glucose solution ( $25 \mathrm{~g}$ of glucose; $280 \mathrm{mOsmol} / \mathrm{L}$ ) for 6 hours after the beginning of anesthesia. Group II received trans-operatively a $6.6 \%$ infusion of L-amino acids (500 mL, $33 \mathrm{~g}$ of amino acids; $620 \mathrm{mOsmol} / \mathrm{L}$ ) and 16.6\% glucose ( $250 \mathrm{~mL}, 42$ of glucose; $920 \mathrm{mOsmol} / \mathrm{L}$ ) by peripheral phleboclysis for 6 hours starting from the beginning of anesthesia. The composition of the L-amino acid solution, in g/L, was: 5.0 isoleucine, 7.4 leucine, 6.6 lysine, 4.3 methionine, 5.1 phenylalanine, 4.4 threonine, 2.0 tryptophan, 6.2 valine, 12.0 arginine, 3.0 histidine, 14.0 glycine, 15.0 alanine 15.0 , and 15.0 proline. The amount of glucose for group I was the same as the usual glucose infusion for patients, while group II received amino acids plus $\sim 75 \%$ of glucose more than group I. Considering that the patient weight range varied less than $10 \%$, all patients received the same amount of glucose and amino acids as planned for group I or group II. Free food and water intake was allowed 48 hours after surgery.

All patients were admitted to the hospital 24 hours before the surgical procedure for nutritional assessment (weight and height) and for biochemical evaluation, urine collection, and 12 hours of pre-anesthesia fasting (Figure 1). Urine was collected with a urine collector device. The results are based on a complete urinary collection period.

Urinary nitrogen excretion was determined by the Kjeldhal [9] method at the following times: P1, 12 hours before anesthesia; P2, trans-operative period up to 6 hours; P3, from 6 to 24 hours; P4, from 24 to 48 hours. Urinary excretion of 15 amino acids was measured [10] during the P1 and P4 periods. Urinary nitrogen mea- 
surements did not cover any extra-renal losses of nitrogen, but was the same throughout the entire protocol. Nitrogen retention was the difference between nitrogen infusion and urinary nitrogen excretion.

Urinary adrenaline was determined [11] by HPLC using a model LC10A Shimadzu ${ }^{\circledR}$ apparatus equipped with an RF35 fluorescence detector and a C18 column packed with OPA HR adsorbosphere, lot 111272 (Allteck, USA).

The results obtained (mean \pm standard error) for the two groups were analyzed statistically by the nonparametric Mann-Whitney test, with the level of significance set at $\mathrm{P}<0.05$. The primary end-point of the study was an increase in nitrogen retention after amino acid infusion.

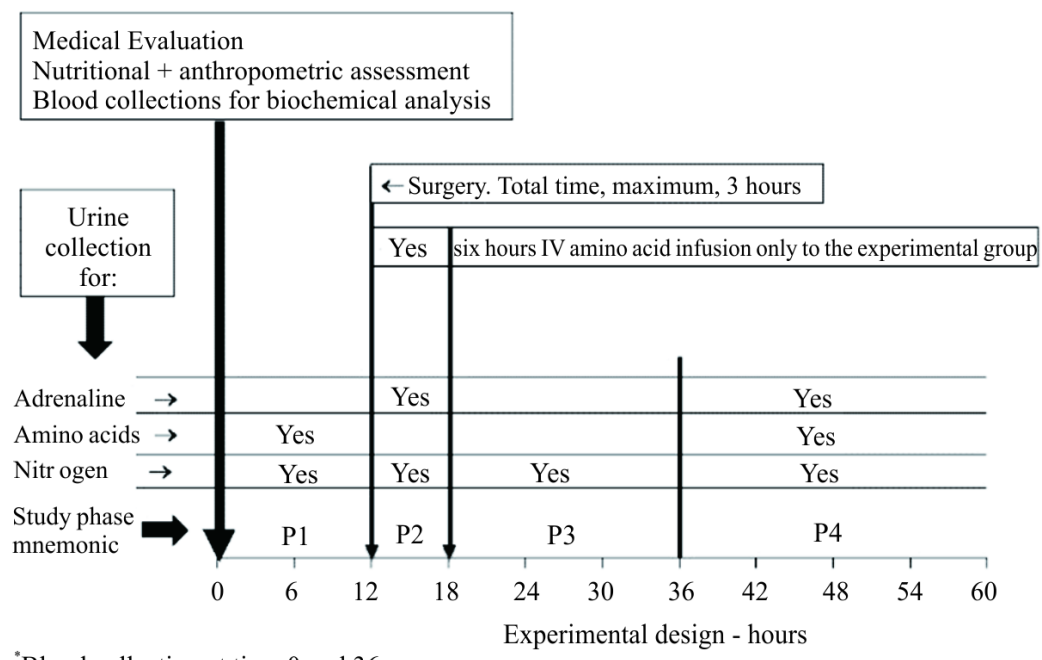

"Blood collection at time 0 and 36 .

Figure 1. Experimental design. Group I was submitted to the standard procedures of the hospital, receiving Ringer's lactate solution in combination with $500 \mathrm{~mL}$ of a $5 \%$ glucose solution ( $25 \mathrm{~g}$ of glucose; $289 \mathrm{mOsmol} / \mathrm{L}$ ). Group II, experimental group, received transoperative of a $6.6 \%$ infusion of L-amino acids, $500 \mathrm{~mL}$ (33 g of amino acids; 620 mOsmol/L) and $16.6 \%$ glucose, $250 \mathrm{~mL} \mathrm{(42} \mathrm{g} \mathrm{of} \mathrm{glucose;}$ $\sim 920 \mathrm{mOsmol} / \mathrm{L})$. Study phase description: P1 $=6$ hours before surgery, fasting period. P2, Group I = 6 hours from the surgery beginning, only glucose infusion. P2, Group II = 6 hours from the surgery beginning, glucose + amino acid infusion. P3 $=18$ hours after P2, Ringer solution $+5 \%$ glucose infusion, booth groups. P4 = 24 hours after P3. Free water and food intake, booth groups, as prescribed by responsible physician.

Table 1. Clinical and biological characteristics of the subjects before surgery*.

\begin{tabular}{ccc}
\hline & Group I $(\mathrm{n}=9)^{\dagger}$ & Group II $(\mathrm{n}=9)^{\ddagger}$ \\
\hline Age (years) & $47 \pm 5^{\S}$ & $54 \pm 7$ \\
Sex & 7 females & 7 females \\
BMI $\left(\mathrm{kg} / \mathrm{m}^{2}\right)$ & 2 males & 2 males \\
Arm skinfold $(\mathrm{mm})$ & $24 \pm 1.3^{\S}$ & $26 \pm 1.0$ \\
Arm circumference $(\mathrm{cm})$ & $19 \pm 1.0^{\S}$ & $21 \pm 0.3$ \\
& $28 \pm 1.3^{\S}$ & $25 \pm 0.7$ \\
Surgery & Cholecystectomy (5) & Cholecystectomy (8) \\
& Subtotal gastrectomy $(1)$ & Subtotal gastrectomy $(1)$ \\
Solution infused during surgery & Splenectomy $(2)$ & \\
& Amputation of the rectum $(1)$ & $750 \mathrm{~mL}$ of a $6.6 \%$ amino acid $+16.6 \%$ glucose \\
& Ringer’s lactate $(5-6 \mathrm{~mL} / \mathrm{kg} / \mathrm{h})+500 \mathrm{~mL}$ & solution followed, if necessary, by Ringer's \\
lactate (5 - 6 mL/kg/h) $+500 \mathrm{~mL} 5 \%$ glucose \\
solution
\end{tabular}

\footnotetext{
${ }^{*}$ Protocol time 0, 12 hours before surgery. See Figure 1 for details. ${ }^{\dagger}$ Control; ${ }^{\ddagger}$ Experimental; ${ }^{\S}$ Mean \pm standard error. P $>0.05$.
} 


\section{Results}

Of the 18 individuals studied, 4 were men and 14 were women and patient age ranged from 32 to 73 years. According to body mass index, besides a history of normal food intake, no edema or low albumin level, there were no obese or malnourished individuals. All subjects presented a good medical nutritional status. Most patients (n = 13) were submitted to standard open cholecystectomy secondary to biliary lithiasis. Blood loss, total fluid infused, surgical time and procedures were similar for all subjects. Table 1 describes the characteristics of the control and experimental subjects.

Urinary nitrogen excretion during the periods evaluated was similar in the two groups studied (Table 2). However, the nitrogen balance was significantly more negative in-group I, which did not receive a trans-operative amino acid infusion (Table 2). In addition, there was no statistically significant difference in urinary amino acid or adrenaline profile between groups (Table 3 ).

Biochemical plasma data, including urea nitrogen, creatinine and glucose, were statistically similar before and after surgery in each group, with no difference between groups (Table 4). There was no need to use exogenous insulin to control glycaemia.

Table 2. Urinary adrenaline, nitrogen data and nitrogen balance during the experimental protocol.

\begin{tabular}{ccc}
\hline Periods $^{*}$ & Group I & Group II \\
P2 & $513 \pm 127^{\dagger}$ & Urinary adrenaline $\mu \mathrm{g} / \mathrm{L}$ \\
P4 & $631 \pm 125$ & $461 \pm 183$ \\
& & $795 \pm 287$ \\
P1 & Urinary nitrogen $\mathrm{g} / \mathrm{hour}$ \\
P2 & $0.56 \pm 0.12$ & $0.67 \pm 0.12$ \\
P3 & $0.63 \pm 0.13$ & $0.95 \pm 0.20$ \\
P4 & $0.58 \pm 0.08$ & $0.49 \pm 0.09$ \\
& $0.39 \pm 0.05$ & $0.39 \pm 0.09$ \\
P1 + P2 + P3 & & Nitrogen balance g/hour \\
Total nitrogen intake & $-0.59 \pm 0.09$ & $-0.25 \pm 0.08$ (P $<0.05)$ \\
\hline
\end{tabular}

"Periods: P1 (12 hours before surgery); P2, 6 hours from the beginning of the anesthetic procedure, P3, 6 to 24 hours after surgery; P4, 24 to 48 hours after surgery. ${ }^{\dagger}$ Mean \pm standard error.

Table 3. Urinary amino acid values, in $\mu \mathrm{mol} / \mathrm{L}$, during the $\mathrm{P} 1$ and $\mathrm{P} 4$ periods.

\begin{tabular}{|c|c|c|c|c|}
\hline & \multicolumn{2}{|c|}{ Group I } & \multicolumn{2}{|c|}{ Group II } \\
\hline & $\mathrm{P} 1^{*}$ & $\mathrm{P} 4^{*}$ & $\mathrm{P} 1^{*}$ & $\mathrm{P} 4^{*}$ \\
\hline Glutamic acid & $49 \pm 14^{\dagger}$ & $28 \pm 4$ & $38 \pm 11$ & $25 \pm 4$ \\
\hline Alanine & $41 \pm 14$ & $89 \pm 35$ & $35 \pm 2$ & $33 \pm 9$ \\
\hline Arginine & $90 \pm 18$ & $98 \pm 29$ & $176 \pm 110$ & $170 \pm 25$ \\
\hline Asparagine & $11 \pm 2$ & $10 \pm 2$ & $11 \pm 3$ & $13 \pm 3$ \\
\hline Phenylalanine & $18 \pm 3$ & $19 \pm 2$ & $20 \pm 4$ & $20 \pm 10$ \\
\hline Glycine & $94 \pm 16$ & $154 \pm 41$ & $120 \pm 33$ & $184 \pm 64$ \\
\hline Glutamine & $10 \pm 3$ & $11 \pm 2$ & $20 \pm 6$ & $9 \pm 1$ \\
\hline Histidine & $64 \pm 12$ & $97 \pm 24$ & $130 \pm 68$ & $134 \pm 29$ \\
\hline Isoleucine & $9 \pm 2$ & $15 \pm 6$ & $17 \pm 6$ & $19 \pm 8$ \\
\hline Leucine & $16 \pm 5$ & $15 \pm 4$ & $18 \pm 4$ & $88 \pm 43$ \\
\hline Lysine & $40 \pm 6$ & $50 \pm 7$ & $55 \pm 14$ & $49 \pm 15$ \\
\hline Methionine & $10 \pm 2$ & $10 \pm 2$ & $20 \pm 8$ & $10 \pm 2$ \\
\hline Tyrosine & $63 \pm 21$ & $104 \pm 55$ & $50 \pm 14$ & $41 \pm 6$ \\
\hline Threonine & $87 \pm 47$ & $55 \pm 13$ & $66 \pm 21$ & $58 \pm 15$ \\
\hline Valine & $18 \pm 4$ & $20 \pm 3$ & $30 \pm 11$ & $19 \pm 4$ \\
\hline
\end{tabular}

*Periods: P1 (12 hours before surgery); P4, 24 to 48 hours after surgery. ${ }^{\dagger}$ Mean \pm standard error. 
Table 4. Biochemical plasma values ${ }^{*}$ before (time 0 ) and after surgery (time 36). See Figure 1 for details.

\begin{tabular}{|c|c|c|c|c|}
\hline & \multicolumn{2}{|c|}{ Group I } & \multicolumn{2}{|c|}{ Group II } \\
\hline & Time $0^{\dagger}$ & Time 36 & Time 0 & Time 36 \\
\hline $\begin{array}{l}\text { Urea nitrogen } \\
\text { mg/dL }\end{array}$ & $25 \pm 3^{\ddagger}$ & $27 \pm 3$ & $27 \pm 3$ & $26 \pm 2$ \\
\hline $\begin{array}{l}\text { Creatinine } \\
\text { mg/dL }\end{array}$ & $0.7 \pm 0.03$ & $0.7 \pm 0.03$ & $0.8 \pm 0.07$ & $0.8 \pm 0.07$ \\
\hline $\begin{array}{l}\text { Sodium } \\
\mathrm{mmol} / \mathrm{L}\end{array}$ & $136 \pm 2$ & $132 \pm 2$ & $136 \pm 1$ & $132 \pm 1$ \\
\hline Potassium mmol/L & $3.6 \pm 0.2$ & $4.0 \pm 0.1$ & $3.9 \pm 0.1$ & $3.9 \pm 0.1$ \\
\hline Aspartate aminotransferase U/L & $57 \pm 13$ & $57 \pm 12$ & $54 \pm 15$ & $58 \pm 16$ \\
\hline Alanine aminotransferase U/L & $43 \pm 11$ & $44 \pm 11$ & $46 \pm 15$ & $49 \pm 16$ \\
\hline Alkaline phosphatase U/L & $74 \pm 11$ & $74 \pm 11$ & $77 \pm 6$ & $116 \pm 46$ \\
\hline $\begin{array}{c}\text { Total bilirubin } \\
\text { mg/dL }\end{array}$ & $0.9 \pm 0.1$ & $1.5 \pm 0.6$ & $0.8 \pm 0.1$ & $2.0 \pm 1.2$ \\
\hline Thromboplastin\% & $74 \pm 0.3$ & $73 \pm 5$ & $82 \pm 3$ & $82 \pm 3.3$ \\
\hline $\begin{array}{l}\text { Albumin } \\
\text { g/dL }\end{array}$ & $42 \pm 2$ & $42 \pm 2$ & $40 \pm 2$ & $40 \pm 2$ \\
\hline $\begin{array}{l}\text { Glucose } \\
\mathrm{mg} / \mathrm{dL}\end{array}$ & $109 \pm 15$ & $112 \pm 15$ & $96 \pm 5$ & $96 \pm 4$ \\
\hline
\end{tabular}

${ }^{*}$ From the local Hospital Central Laboratory of Clinical Analysis. ${ }^{\dagger}$ Time $0=12$ hours before surgery. Time $36=24$ hours after end of the surgery. See Figure 1. ${ }^{\ddagger}$ Mean \pm standard error.

\section{Discussion}

The infusion of extra glucose and amino acids during the trans-operative period did not change glycaemia, urinary excretion of nitrogen or amino acids during the postoperative period, but improved the nitrogen balance immediately after surgery. Despite a similar rate of urinary nitrogen excretion per hour, group II retained about $40 \%$ more nitrogen than group I. A glucose-containing solution was chosen for the present protocol in order to avoid hypoglycemia during or after surgery. The offer of a glucose solution plus amino acids spared nitrogen for protein anabolism or at least maintained the nitrogen balance [12].

Although experimental protocols like the present one are not frequently used, the results obtained here showed a beneficial effect of amino acid infusion during surgery, with nitrogen retention and without changes in plasma levels of nitrogen products such as urea or changes in urinary amino acid excretion. In addition, the amino acid infusion did not cause additional stress for the patient, as shown by similar urinary adrenaline values in both groups. Similarly, the nitrogen balance was also found to be positive in patients with diabetes type 2 [13] receiving an intravenous amino acid infusion, who were hypercatabolic after colorectal surgeries. Reversal of the nitrogen balance occurs in these patients without causing hyperglycemia [13]. Besides, a rigid blood glucose control did not show any improvement [14].

This greater nitrogen retention, with maintained urinary nitrogen loss, is important if we consider that healthy persons synthesize about $180 \mathrm{~g}$ of muscle per day. To this end, there must be an offer of protein nitrogen through the diet and through efficient re-absorption of intestinal juices [15]. During trauma, such as the metabolic response to surgery, protein losses negatively affect the clinical course of patients. Patients who receive an amino acid infusion during the postoperative period present greater incorporation of 13C-leucine into ileum protein [16], showing that it is possible to maintain and/or recover ileum protein synthesis capacity by infusing amino acids in surgical patients.

It seems increasingly clear that the most habitual protocol, i.e., infusion of a low concentration of glucose or triacylglycerides during the operative period, is inefficient in maintaining an adequate nitrogen balance [17]. Similarly, the sole infusion of an amino acid solution4 is of little clinical benefit after major surgeries. Also, total parenteral nutrition 24 hours before and after surgery does not prevent protein loss during the immediate postoperative period [18].

In the present study, the urinary amino acid profile did not differ significantly between the groups studied. Thus, considering the similarities between groups, we may suggest that neither the infusion of amino acids and 
glucose during the trans-operative period nor the surgical procedure itself induced different situations of metabolic stress between groups. The determinations of amino acids that are eliminated into urine or even their serum concentrations are useful to guide the amino acid composition of these solutions in the presence of catabolic stress before surgery [19]. The nitrogen balance was higher for surgical patients receiving individualized solutions compared to control, showing the advantages of the manipulation of amino acid composition in terms of nitrogen retention.

In the search for more specific functions of certain amino acids in the composition of these solutions, some studies have looked for more effective formulations, for the protection against catabolism and the maintenance of nutritional status after surgery. When a solution enriched with amino acids [20] is employed, a positive nitrogen balance after surgery is reached 2 days earlier than observed with the solution habitually employed for postoperative support. This schedule leads to a more rapid normalization of serum amino acids and improves protein synthesis, with considerable advantages in terms of the recovery of nutritional status. Perioperative nutritional support is also useful to improve the health status of patients undergoing major elective oncological surgery in whom no oral intake is anticipated for 7 to 10 days postoperative or of patients with severe preoperative malnutrition [21].

Surgeries of medium and high complexity were considered for the present study for the evaluation of metabolic stress, of the impact of glucose infusion, and of the nitrogen balance obtained. The use of the present protocol did not increase surgical stress, as suggested by the similar urinary excretion of adrenaline observed in the two groups. The use of amino acids during the anesthesia period may be of advantage in terms of nitrogen metabolism and may increase thermogenesis, inhibiting hypothermia during the postoperative period [22] [23]. The total number of subjects studied was considered adequate because the full protocol was long, and experimental protocols with human beings are always difficult to perform and control.

With advantages over previously used or more habitual procedures such as the discontinuation of any parenteral offer or the choice of glucose solutions of low concentration, the infusion of amino acids and glucose during surgery, by leaving urinary amino acid levels unchanged and inducing a less negative nitrogen balance, suggests the occurrence of nitrogen incorporation into tissue. This may be useful for an early patient recovery, especially in the presence of previous malnutrition or of high surgical stress, preventing protein catabolism.

\section{Conclusion}

The results obtained in the present study permit us to recommend amino acid plus glucose infusion during the trans-operative period in order to prevent or reduce the negative impact of surgical stress on the nutritional status of the patient, favoring a better clinical course.

\section{Acknowledgements}

The present study was supported by grants from the Brazilian Conselho Nacional de Pesquisa-CNPq (no. 306824). There are no conflicts of interest associated with the present study.

\section{References}

[1] Sun, X., Oberlander, D., Huang, J. and Weissman, C. (1998) Fluid Resuscitation, Nutritional Support, and Cholesterol in Critically Ill Postsurgical Patients. Journal of Clinical Anesthesia, 10, 302-308. http://dx.doi.org/10.1016/S0952-8180(98)00032-4

[2] Cammu, G., Vermeiren, K., Lecomte, P., Gendt, S.D., Deloof, T. and Foubert, L. (2009) Perioperative Blood Glucose Management in Patients Undergoing Tumor Hepatectomy. Journal of Clinical Anesthesia, 21, 329-335. http://dx.doi.org/10.1016/j.jclinane.2008.09.006

[3] Tannus, A.F.S., Carvalho, R.L.V., Suen, V.M.M., Cardoso, J.B., Okano, N. and Marchini, J.S. (2001) Energy Expenditure after 2- to 3-Hour Elective Surgical Operations. Revista do Hospital das Clínicas, 56, 37-40. http://dx.doi.org/10.1590/S0041-87812001000200001

[4] Collins, J.P., Oxby, C.B. and Hill, G.L. (1978) Intravenous Amino Acids and Intravenous Hyperalimentation as Protein-Sparing Therapy after Major Surgery. A Controlled Clinical Trial. Lancet, 8068, 788-791. http://dx.doi.org/10.1016/S0140-6736(78)92995-1

[5] Soop, M., Nygren, J., Thorell, A., Weidenhielm, L., Lundberg, M., Hammarqvist, F., et al. (2004) Preoperative Oral Carbohydrate Treatment Attenuates Endogenous Glucose Release 3 Days after Surgery. Clinical Nutrition, 23, 733- 
741. http://dx.doi.org/10.1016/j.clnu.2003.12.007

[6] Chambrier, C., Aouifi, A., Bon, C., Saudin, F., Paturel, B. and Bouletreau, P. (1999) Effects of Intraoperative Glucose Administration on Circulating Metabolites and Nitrogen Balance during Prolonged Surgery. Journal of Clinical Anesthesia, 11, 646-651. http://dx.doi.org/10.1016/S0952-8180(99)00114-2

[7] Helminen, H., Raitanen, M. and Kellosalo, J. (2007) Immunonutrition in Elective Gastrointestinal Surgery Patients. Scandinavian Journal of Surgery, 96, 46-50.

[8] Wolters, U., Wolf, T., Stützer, H. and Schroder, T. (1996) ASA Classification and Perioperative Variables as Predictors of Postoperative Outcome. British Journal of Anaesthesia, 77, 217-222. http://dx.doi.org/10.1093/bja/77.2.217

[9] Kjeldahl, J. (1883) Neue methods zurbestimmung des stickstoffs in organischenkorpern. Zeitschrift für Analytische Chemie, 22, 366-382. http://dx.doi.org/10.1007/BF01338151

[10] Carducci, C., Birarelli, M., Leuzzi, V., Santagata, G., Serafini, P. and Antonozzi, I. (1996) Automated Method for the Measurement of Amino Acids in Urine by High-Performance Liquid Chromatography. Journal of Chromatography A, 729, 173-180. http://dx.doi.org/10.1016/0021-9673(95)00964-7

[11] Jeon, H.K., Nohta, H. and Ohkura, Y. (1992) High-Performance Liquid Chromatographic Determination of Catecholamines and Their Precursor and Metabolites in Human Urine and Plasma by Postcolumn Derivatization Involving Chemical Oxidation Followed by Fluorescence Reaction. Analytical Biochemistry, 200, 332-338. http://dx.doi.org/10.1016/0003-2697(92)90474-L

[12] Kruimel, J.W., Naber, T.H., van der Vliet, J.A., Carneheim, C., Katan, M.B. and Jansen, J.B. (2001) Parenteral Structured Triglyceride Emulsion Improves Nitrogen Balance and Is Cleared Faster from the Blood in Moderately Catabolic Patients. Journal of Parenteral and Enteral Nutrition, 25, 237-244. http://dx.doi.org/10.1177/0148607101025005237

[13] Lugli, A.K., Donatelli, F., Schricker, T., Wykes, L. and Carli, F. (2008) Epidural Analgesia Enhances the Postoperative Anabolic Effect of Amino Acids in Diabetes Mellitus Type 2 Patients Undergoing Colon Surgery. Anesthesiology, 108, 1093-1099. http://dx.doi.org/10.1097/ALN.0b013e3181730239

[14] Chan, R.P.C., Galas, F.R.B.G., Hajjar, L.A., Bello, C.N., Piccioni, M.A. and Auler, J.O.C. (2009) Intensive Perioperative Glucose Control Does Not Improve Outcomes of Patients Submitted to Open-Heart Surgery: A Randomized Controlled Trial. Clinics, 64, 51-60. http://dx.doi.org/10.1590/S1807-59322009000100010

[15] Marchini, J.S., Moreira, E.A.M., Moreira, M.Z., Hiramatsu, T., Oliveira, J.E.D. and Vannucchi, H. (1996) Whole Body Protein Metabolism Turnover in Men on a High or Low Calorie Rice and Bean Brazilian Diet. Nutrition Research, 16, 435-441. http://dx.doi.org/10.1016/0271-5317(96)00025-5

[16] Rittler, P., Kuppinger, D., Krick, M., Demmelmair, H., Koletzko, B., Jauch, K.W. and Hartl, W.H. (2009) Differential Regulation of Protein Synthesis in Hepatic and Intestinal Tissues by Amino Acids: Studies in Patients Recovering from Major Abdominal Operations. Surgery, 146, 113-121. http://dx.doi.org/10.1016/j.surg.2009.03.021

[17] Svanfeldt, M., Thorell, A., Nygren, J. and Ljungqvist, O. (2006) Postoperative Parenteral Nutrition While Proactively Minimizing Insulin Resistance. Nutrition, 22, 457-464. http://dx.doi.org/10.1016/j.nut.2005.06.013

[18] López-Hellin, J., Baena-Fustegueras, J.A., Vidal, M., Riera, S.S. and García-Arumí, E. (2004) Perioperative Nutrition Prevents the Early Protein Losses in Patients Submitted to Gastrointestinal Surgery. Clinical Nutrition, 23, 1001-1008. http://dx.doi.org/10.1016/j.clnu.2003.12.006

[19] Berard, M.P., Pelletier, A., Ollivier, J.M., Gentil, B. and Cynober, L. (2002) Qualitative Manipulation of Amino Acid Supply during Total Parenteral Nutrition in Surgical Patients. Journal of Parenteral and Enteral Nutrition, 26, 136-143. http://dx.doi.org/10.1177/0148607102026002136

[20] Wang, X.Y., Li, N., Gu, J., Li, W.Q. and Li, J.S. (2003) The Effects of the Formula of Amino Acids Enriched BCAA on Nutritional Support in Traumatic Patients. World Journal of Gastroenterology, 9, 599-602.

[21] Heslin, M.J. and Brennan, M.F. (2000) Advances in Perioperative Nutrition: Cancer. World Journal of Surgery, 24, 1477-1485. http://dx.doi.org/10.1007/s002680010265

[22] Sellden, E. and Lindahl, S.G.E. (1998) Postoperative Nitrogen Excretion after Amino Acid-Induced Thermogenesis under Anesthesia. Anesthesia \& Analgesia, 87, 641-646. http://dx.doi.org/10.1097/00000539-199809000-00029

[23] Moriyama, T., Tsuneyoshi, I., Omae, T., Takeyama, M. and Kanmura, Y. (2008) The Effect of Amino-Acid Infusion during Off-Pump Coronary Arterial Bypass Surgery on Thermogenic and Hormonal Regulation. Journal of Anesthesia, 22, 354-360. http://dx.doi.org/10.1007/s00540-008-0651-1 